\title{
Initial Rotor Position Estimation of an Interior Permanent-Magnet Synchronous Machine Using Carrier-Frequency Injection Methods
}

\author{
Yu-seok Jeong, Student Member, IEEE, Robert D. Lorenz, Fellow, IEEE, Thomas M. Jahns, Fellow, IEEE, and \\ Seung-Ki Sul, Fellow, IEEE
}

\begin{abstract}
This paper presents a method using carrier-frequency injection to estimate the initial rotor position and magnetic polarity for an interior permanent-magnet synchronous machine. A nonsaturating inductance model of the machine provides no information about the polarity of the rotor magnet because the position observer based on this model is locally stable at both poles. To distinguish the polarity of the rotor magnet, the magnetic saturation effect can be used. The Taylor series can be used to describe the nonlinear magnetic saturation relationship between the current and the flux linkage in the $d$-axis rotor reference frame. The second-order term produces the second harmonic component of the carrier frequency, and the sign of its coefficient identifies the polarity of the rotor magnet being tracked. Both simulation and experimental results show good response of the position observer at several rotor electrical positions using either a rotating vector in the stationary reference frame or a oscillating vector in the estimated rotor reference frame.
\end{abstract}

Index Terms-Carrier-frequency injection, initial rotor position, magnetic polarity, second harmonic component.

\section{INTRODUCTION}

$\mathbf{I}$ NTERIOR permanent-magnet (IPM) synchronous machines are attractive candidates for high-performance applications because of their high efficiency and suitability for wide speed ranges of constant power operation [1]. In recent years, several papers have been published describing methods for the elimination of position sensors in both induction and permanent-magnet synchronous machines using signal injection, saliency-tracking techniques. The methods suitable for zero and very low speed operation are primarily based on injecting

Paper IPCSD-04-062, presented at the 2003 IEEE International Electric Machines and Drives Conference, Madison, WI, June 1-4, and approved for publication in the IEEE TRANSACTIONS ON INDUSTRY APPLICATIONS by the Industrial Drives Committee of the IEEE Industry Applications Society. Manuscript submitted for review March 1, 2004 and released for publication August 30, 2004. This work was supported in part by the Wisconsin Electric Machines and Power Electronics Consortium (WEMPEC), University of Wisconsin, Madison.

Y. Jeong and S.-K. Sul are with the School of Electrical Engineering and Computer Sciences, Seoul National University, Seoul 151-744, Korea (e-mail: yu-seok@eepel.snu.ac.kr; sulsk@plaza.snu.ac.kr).

R. D. Lorenz is with the Department of Mechanical Engineering and the Department of Electrical and Computer Engineering, University of Wisconsin, Madsion, WI 53706 USA (e-mail: lorenz@engr.wisc.edu).

T. M. Jahns is with the Department of Electrical and Computer Engineering, University of Wisconsin, Madsion, WI 53706 USA (e-mail: jahns@engr.wisc.edu).

Digital Object Identifier 10.1109/TIA.2004.840978 a carrier-frequency signal with small amplitude using either a rotating vector in the stationary reference frame [2], [3] or an oscillating vector in the estimated rotor reference frame [4], [5] to track a spatial saliency. The IPM synchronous machine is well suited for these techniques because the inductance difference between the $d$ - and $q$-axes in the rotor reference frame provides a large spatial saliency that is inherent to this type of machine.

Unfortunately, the carrier signal derived from the stator inductance model with linear relationship between the flux linkage and the corresponding axis current in the rotor reference frame provides ambiguous information about the polarity of the rotor magnet because the inductances in this model vary periodically as a second spatial harmonic. The saturation effect of the rotor magnet flux path has been used to estimate the initial rotor position and polarity. Square waves [6] and short pulses [7] have been applied to identify the difference in inductance between the north and the south poles due to the effect of saturation. A rotating current vector in the stationary reference frame [8] and an oscillating current vector in the estimated rotor reference frame [9] were also used to distinguish the magnetic polarity. Nonetheless, a sinusoidal voltage is typically used as the carrier signal in most self-sensing control implementations, making it very desirable to develop a polarity identification method that uses a sinusoidal voltage signal [10].

This paper describes a scheme to distinguish the polarity of the rotor magnet using either a rotating voltage vector in the stationary reference frame or an oscillating vector in the estimated frame by modeling the saturation effect of the $d$-axis flux linkage in the rotor reference frame. The heterodyning process to extract the position information as well as the polarity and the Luenberger-style observer to estimate the rotor position are also discussed.

\section{SATURATEd FluX LinKage Model}

The magnetization curve of an IPM synchronous machine is shown in Fig. 1 . The variables are $d$-axis components in the rotor reference frame and $\Lambda_{m}$ denotes the flux linkage of the rotor magnet without stator current. A positive $d$-axis current increases the stator iron saturation, resulting in a decreased $d$-axis inductance, and vise versa. This effect can be used to track the north pole of the rotor magnet. 


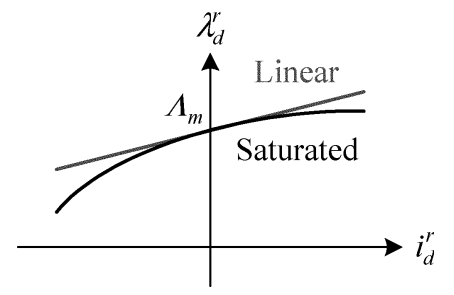

Fig. 1. Flux linkage versus applied current in the rotor reference frame.

For the case of current injection, the $d$-axis flux linkage can be approximated with respect to the injected $d$-axis current by the Taylor series dropping higher order terms than the second order

$$
\lambda_{d}^{r} \approx \Lambda_{m}+L_{d} i_{d}^{r}+\frac{1}{2} \frac{d^{2} \lambda_{d}^{r}}{d i_{d}^{r 2}}(0) i_{d}^{r 2}
$$

where $L_{d}=\left(d \lambda_{d}^{r} / d i_{d}^{r}\right)(0)$ and $\left(d^{2} \lambda_{d}^{r} / d i_{d}^{r 2}\right)(0)<0$.

When a high-frequency current is injected at standstill, the stator resistive voltage drop can be neglected. Thus the $d$-axis voltages at both poles are

$$
\begin{aligned}
& v_{+d}^{r} \approx \frac{d \lambda_{+d}^{r}}{d t}=L_{d} \frac{d i_{+d}^{r}}{d t}+\frac{d^{2} \lambda_{d}^{r}}{d i_{d}^{r 2}}(0) i_{+d}^{r} \frac{d i_{+d}^{r}}{d t} \\
& v_{-d}^{r} \approx \frac{d \lambda_{-d}^{r}}{d t}=L_{d} \frac{d i_{-d}^{r}}{d t}-\frac{d^{2} \lambda_{d}^{r}}{d i_{d}^{r 2}}(0) i_{-d}^{r} \frac{d i_{-d}^{r}}{d t}
\end{aligned}
$$

where the subscript $+d$ and $-d$ denote the north pole and the south pole, respectively. The sum of any variable at both axes should be zero.

For the case of voltage injection, it is better to describe the $d$-axis current as a function of the $d$-axis flux linkage by the Taylor series

$$
i_{d}^{r} \approx \frac{1}{L_{d}}\left(\lambda_{d}^{r}-\Lambda_{m}\right)+\frac{1}{2} \frac{d^{2} i_{d}^{r}}{d \lambda_{d}^{r 2}}\left(\Lambda_{m}\right)\left(\lambda_{d}^{r}-\Lambda_{m}\right)^{2}
$$

where $\left(d^{2} i_{d}^{r} / d \lambda_{d}^{r 2}\right)\left(\Lambda_{m}\right)>0$.

When a high-frequency voltage is injected at standstill, the $d$-axis currents at both poles are

$$
\begin{aligned}
& i_{+d}^{r} \approx \frac{1}{L_{d}} \int v_{+d}^{r} d t+\frac{1}{2} \frac{d^{2} i_{d}^{r}}{d \lambda_{d}^{r 2}}\left(\Lambda_{m}\right)\left(\int v_{+d}^{r} d t\right)^{2} \\
& i_{-d}^{r} \approx \frac{1}{L_{d}} \int v_{-d}^{r} d t-\frac{1}{2} \frac{d^{2} i_{d}^{r}}{d \lambda_{d}^{r 2}}\left(\Lambda_{m}\right)\left(\int v_{-d}^{r} d t\right)^{2} .
\end{aligned}
$$

In both cases, the coefficient signs of the second terms in (2) and (4) can be used to distinguish the polarity of the rotor magnet at the estimated position. It should be noted that the saturation effect in $q$-axis is not available for the polarity detection if the center of the operating point at the $q$ axis is zero because the $q$-axis flux linkage is an odd function of the $q$-axis current and thus has no even-order terms when expressed by the Taylor series with center of the origin.

\section{IPM MACHINE MODEL FOR CARRIER INJECTION}

The stator voltage model for an IPM synchronous machine in the stationary reference frame can be written in complex space vector form as follows:

$$
\boldsymbol{v}_{\boldsymbol{d q}}^{\boldsymbol{s}}=R_{s} \boldsymbol{i}_{\boldsymbol{d q}}^{\boldsymbol{s}}+\frac{d}{d t} \lambda_{d q}^{\boldsymbol{s}}
$$

Since the resistive voltage drop is small relative to the induced voltage at the injected carrier frequency, the carrier components of the $d$ - and $q$-axes currents in the rotor reference frame can be approximated by

$$
\begin{aligned}
& i_{d c}^{r} \approx \frac{1}{2 L_{d}}\left(\lambda_{d q c}^{r}+\lambda_{d q c}^{r *}\right)+\frac{1}{8} \frac{d^{2} i_{d}^{r}}{d \lambda_{d}^{r 2}}\left(\Lambda_{m}\right)\left(\lambda_{d q c}^{r}+\lambda_{d q c}^{r *}\right)^{2} \\
& =\frac{1}{2 L_{d}}\left(\int \boldsymbol{v}_{\boldsymbol{d} \boldsymbol{s} \boldsymbol{c}}^{\boldsymbol{s}} d t e^{-j \theta_{r}}+\int \boldsymbol{v}_{\boldsymbol{d} \boldsymbol{s} \boldsymbol{c}}^{\boldsymbol{s *}} d t e^{j \theta_{r}}\right) \\
& +\frac{1}{8} \frac{d^{2} i_{d}^{r}}{d \lambda_{d}^{r 2}}\left(\Lambda_{m}\right)\left(\int \boldsymbol{v}_{\boldsymbol{d} \boldsymbol{s} \boldsymbol{c}}^{\boldsymbol{s}} d t e^{-j \theta_{r}}+\int \boldsymbol{v}_{\boldsymbol{d} \boldsymbol{q} \boldsymbol{c}}^{\boldsymbol{s *}} d t e^{j \theta_{r}}\right)^{2} \\
& i_{q c}^{r} \approx \frac{1}{j 2 L_{q}}\left(\lambda_{d q c}^{r}-\lambda_{d q c}^{r *}\right) \\
& =\frac{1}{j 2 L_{q}}\left(\int \boldsymbol{v}_{\boldsymbol{d} \boldsymbol{s} \boldsymbol{c}}^{\boldsymbol{s}} d t e^{-j \theta_{r}}-\int \boldsymbol{v}_{\boldsymbol{d} \boldsymbol{q} \boldsymbol{c}}^{\boldsymbol{s *}} d t e^{j \theta_{r}}\right)
\end{aligned}
$$

where the asterisk in the superscript denotes complex conjugate. This yields the carrier current vector in the stationary reference frame in terms of the carrier voltage vector as follows:

$$
\begin{aligned}
\boldsymbol{i}_{\boldsymbol{d} \boldsymbol{s} \boldsymbol{c}}^{\boldsymbol{s}}= & \boldsymbol{i}_{\boldsymbol{d} \boldsymbol{q} \boldsymbol{c}} e^{j \theta_{r}}=i_{d c}^{r} e^{j \theta_{r}}+j i_{q c}^{r} e^{j \theta_{r}} \\
= & \frac{1}{2}\left(\frac{1}{L_{d}}+\frac{1}{L_{q}}\right) \int \boldsymbol{v}_{\boldsymbol{d} \boldsymbol{c} \boldsymbol{c}}^{\boldsymbol{s}} d t+\frac{1}{2}\left(\frac{1}{L_{d}}-\frac{1}{L_{q}}\right) \\
& \times \int \boldsymbol{v}_{\boldsymbol{d} \boldsymbol{q} \boldsymbol{c}}^{\boldsymbol{s *}} d t e^{j 2 \theta_{r}}+\frac{1}{8} \frac{d^{2} i_{d}^{r}}{d \lambda_{d}^{r 2}}\left(\Lambda_{m}\right) \\
& \times\left(\int \boldsymbol{v}_{\boldsymbol{d} \boldsymbol{c} \boldsymbol{c}}^{\boldsymbol{s}} d t e^{-j \theta_{r}}+\int \boldsymbol{v}_{\boldsymbol{d q} \boldsymbol{c}}^{\boldsymbol{s *}} d t e^{j \theta_{r}}\right)^{2} e^{j \theta_{r}} .
\end{aligned}
$$

\section{SignAl InJeCtion AND PROCESSING}

\section{A. Rotating Voltage Vector in the Stationary Reference Frame}

The rotating vector injection method in the stationary reference frame superimposes a continuously rotating, balanced three-phase carrier-frequency voltage vector onto the fundamental component voltage vector as shown in Fig. 2(a). The interaction between the carrier-frequency voltage vector and the magnetic saliency in the IPM synchronous machine produces a 


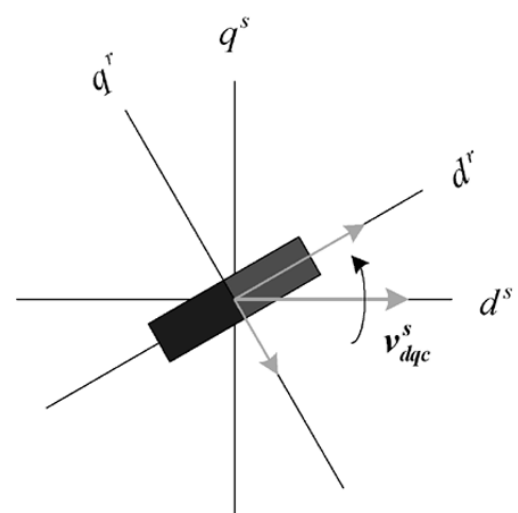

(a)

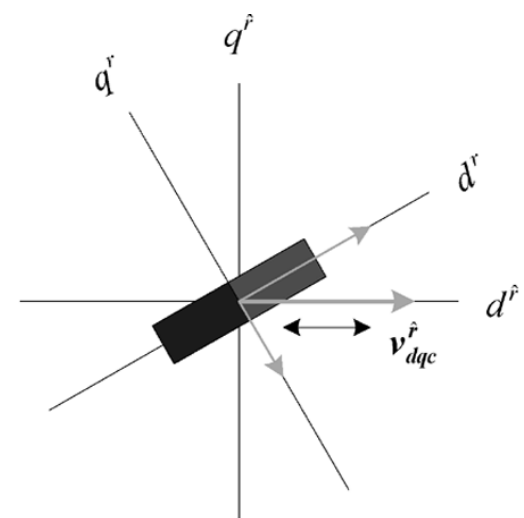

(b)

Fig. 2. Carrier voltage vectors. (a) Rotating vector in the stationary reference frame. (b) Oscillating vector in the estimated rotor reference frame.

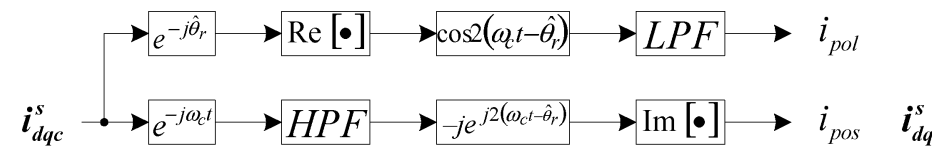

(a)

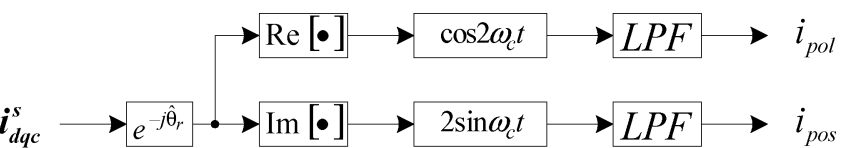

(b)

Fig. 3. Heterodyning process to extract the information about the polarity error and the position error. (a) Rotating vector in the stationary reference frame. (b) Oscillating vector in the estimated rotor reference frame.

carrier-frequency current signal that contains information about the position of the saliency as follows:

$$
\begin{aligned}
\boldsymbol{v}_{\boldsymbol{d} \boldsymbol{q} \boldsymbol{c}}^{\boldsymbol{s}}= & V_{c}\left(\cos \omega_{c} t+j \sin \omega_{c} t\right) \\
\boldsymbol{i}_{\boldsymbol{d} \boldsymbol{q} \boldsymbol{c}}^{\boldsymbol{s}}= & \frac{V_{c}}{j 2 \omega_{c}}\left\{\left(\frac{1}{L_{d}}+\frac{1}{L_{q}}\right) e^{j \omega_{c} t}-\left(\frac{1}{L_{d}}-\frac{1}{L_{q}}\right) e^{-j\left(\omega_{c} t-2 \theta_{r}\right)}\right\} \\
& +\frac{V_{c}^{2}}{2 \omega_{c}^{2}} \frac{d^{2} i_{d}^{r}}{d \lambda_{d}^{r 2}}\left(\Lambda_{m}\right) \sin ^{2}\left(\omega_{c} t-\theta_{r}\right) e^{j \theta_{r}} .
\end{aligned}
$$

The carrier-frequency current can be seen to consist of both positive and negative components relative to the carrier-frequency voltage excitation signal. The positive-sequence component contains no spatial information, but the negative-sequence component contains the desired information about the inductance saliency in its phase. It is noted that the amplitude of the third term containing the magnet polarity information is very small compared to the negative-sequence term that contains the spatial information associated with the IPM machine saliency.

The heterodyning and synchronous frame filtering process depicted in Fig. 3(a) extracts the negative-sequence term to obtain the position error and the saturation term to distinguish the magnetic polarity. The output currents of the signal process contain the polarity information and the position information, respectively, as follows:

$$
\begin{aligned}
& i_{\text {pol }}=-\frac{V_{c}^{2}}{8 \omega_{c}^{2}} \frac{d^{2} i_{d}^{r}}{d \lambda_{d}^{r 2}}\left(\Lambda_{m}\right) \cos 2\left(\theta_{r}-\hat{\theta}_{r}\right) \cos \left(\theta_{r}-\hat{\theta}_{r}\right) \\
& i_{\text {pos }} \approx \frac{V_{c}}{2 \omega_{c}}\left(\frac{1}{L_{d}}-\frac{1}{L_{q}}\right) \sin 2\left(\theta_{r}-\hat{\theta}_{r}\right) .
\end{aligned}
$$

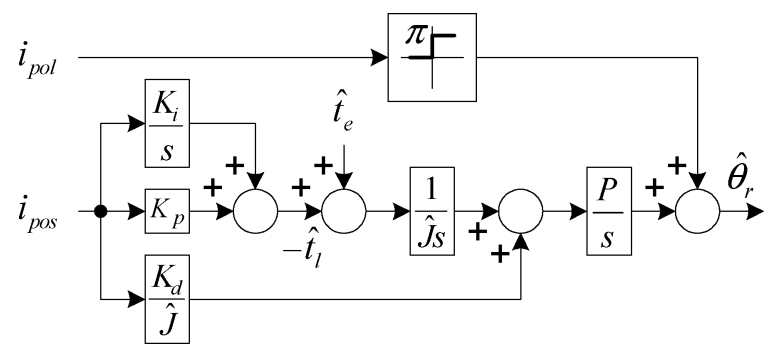

Fig. 4. Trajectory of the current error vector in the rotor reference frame.

TABLE I

MOTOR PARAMETERS

\begin{tabular}{lll}
\hline \hline Symbol & \multicolumn{1}{c}{ Quantity } & \multicolumn{1}{c}{ Value (Unit) } \\
& \multicolumn{1}{c}{ rated current } & $300(\mathrm{~A})$ \\
$P$ & pole pairs & 4 \\
$R_{S}$ & stator resistance & $8.4(\mathrm{~m} \Omega)$ \\
$L_{d}$ & stator d-axis inductance & $100(\mu \mathrm{H})$ \\
$L_{q}$ & stator q-axis inductance & $300(\mu \mathrm{H})$ \\
$\Lambda_{m}$ & rotor magnet flux linkage & $12.26(\mathrm{mV} \cdot \mathrm{s})$ \\
\hline \hline
\end{tabular}

A high-pass filter in the carrier reference frame [3] is used to remove the positive-sequence term and to extract the desired position information that yields negligible distortion with the least spectral separation in the input signals. In general, the high-pass break frequency is chosen to be sufficiently low so that negligible distortion occurs in the desired content. The position error can be obtained by using a demodulator [2]. With regards to the saturation term, a demodulator in the estimated rotor reference frame is used and the sign of its output depends on the tracked polarity. 


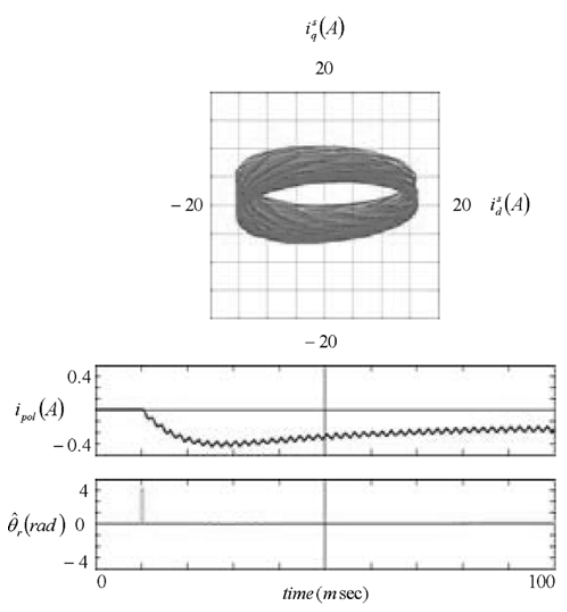

(a)

$i_{q}^{s}(A)$

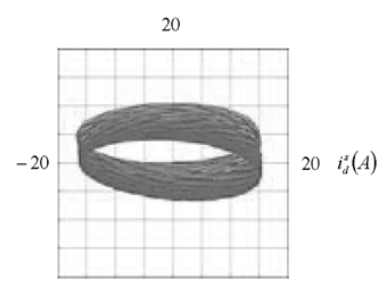

$-20$
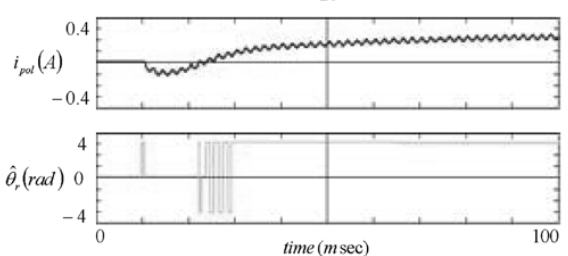

(e)

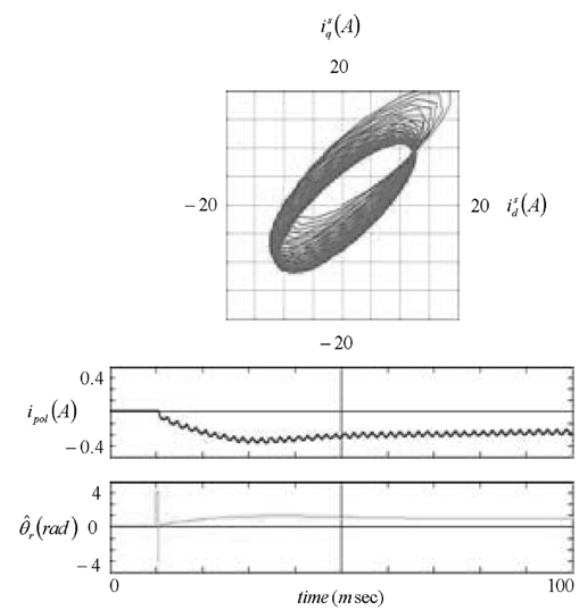

(b)

$i_{q}^{s}(A)$

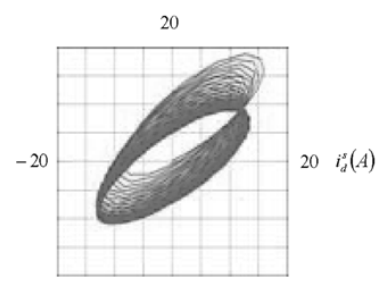

$-20$
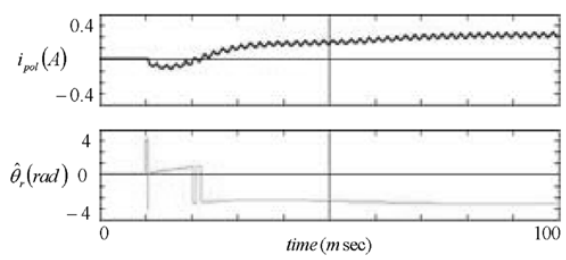

(e)

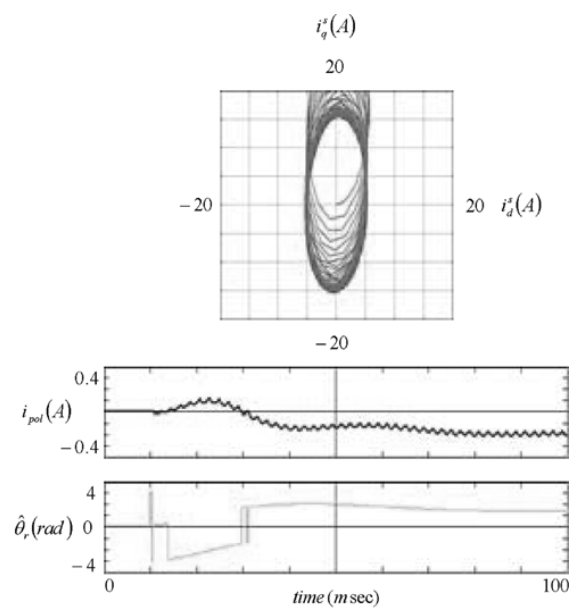

(c)

$i_{q}^{s}(A)$

20
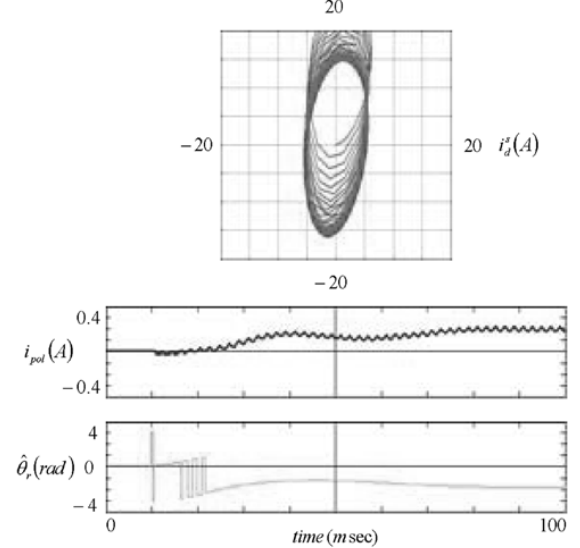

(f)

Fig. 5. Rotating vector injection at multiples of $0.25 \pi \mathrm{rad}$ (simulation). (a) $0 \mathrm{rad}$. (b) $0.25 \pi \mathrm{rad}$. (c) $0.5 \pi \mathrm{rad}$. (d) $-\pi \mathrm{rad}$. (e) $-0.75 \pi \mathrm{rad}$. (f) $-0.5 \pi \mathrm{rad}$.

\section{B. Oscillating Voltage Vector in the Estimated Rotor Reference Frame}

The oscillating vector injection method superimposes a $d$-axis sinusoidal carrier signal in the estimated rotor reference frame onto the fundamental component voltage vector as shown in Fig. 2(b). This signal can be interpreted as the sum of two vectors rotating simultaneously with the same amplitude but in the opposite direction. Assuming that the carrier frequency is sufficiently high compared with the estimated rotor speed, the voltage and current in the estimated rotor reference frame can be expressed as follows:

$$
\begin{aligned}
\boldsymbol{v}_{\boldsymbol{d} \boldsymbol{q} \boldsymbol{c}}^{\hat{\boldsymbol{r}}}= & V_{c} \cos \omega_{c} t \\
\boldsymbol{i}_{\boldsymbol{d} q \boldsymbol{c}}^{\hat{r}}= & \frac{V_{c}}{2 \omega_{c}}\left\{\left(\frac{1}{L_{d}}+\frac{1}{L_{q}}\right)+\left(\frac{1}{L_{d}}-\frac{1}{L_{q}}\right) e^{j 2\left(\theta_{r}-\hat{\theta}_{r}\right)}\right\} \sin \omega_{c} t \\
& +\frac{V_{c}^{2}}{2 \omega_{c}^{2}} \frac{d^{2} i_{d}^{r}}{d \lambda_{d}^{r 2}}\left(\Lambda_{m}\right) \sin ^{2} \omega_{c} t \cos ^{2}\left(\theta_{r}-\hat{\theta}_{r}\right) e^{j\left(\theta_{r}-\hat{\theta}_{r}\right)}
\end{aligned}
$$

The carrier-frequency current for this oscillating vector injection in the estimated rotor reference frame has the desired inductance saliency information in its amplitude, while the same in- formation is in the phase of the carrier-frequency current for the rotating vector injection in the stationary reference frame. The $q$-axis current component is more suitable than the $d$-axis one to extract the desired information about the inductance saliency. The second harmonic component of the $d$-axis current provides the magnet polarity information.

The heterodyning process in Fig. 3(b) extracts the polarity information and the position information as follows:

$$
\begin{aligned}
& i_{p o l}=-\frac{V_{c}^{2}}{8 \omega_{c}^{2}} \frac{d^{2} i_{d}^{r}}{d \lambda_{d}^{r 2}}\left(\Lambda_{m}\right) \cos ^{2}\left(\theta_{r}-\hat{\theta}_{r}\right) \cos \left(\theta_{r}-\hat{\theta}_{r}\right) \\
& i_{p o s}=\frac{V_{c}}{2 \omega_{c}}\left(\frac{1}{L_{d}}-\frac{1}{L_{q}}\right) \sin 2\left(\theta_{r}-\hat{\theta}_{r}\right) .
\end{aligned}
$$

The $q$-axis component at the carrier frequency is used to obtain the position error and the $d$-axis component at the second harmonic frequency is used to identify the magnet polarity. It should be noted that the break frequency of the low-pass filter for the position error term should be chosen to be sufficiently high, otherwise, the observer performance can be deteriorated.

\section{POSITION OBSERVER}

The observer design shown in Fig. 4 reflects several important considerations for achieving high-performance position 


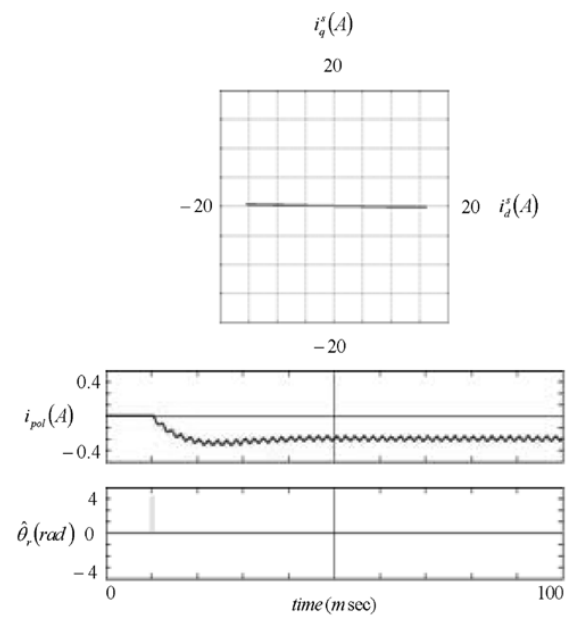

(a)

$i_{q}^{x}(A)$

20

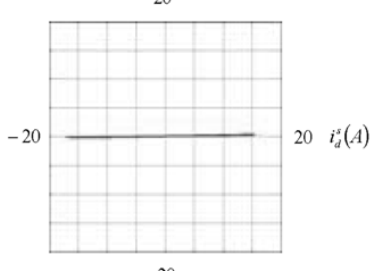

$-20$
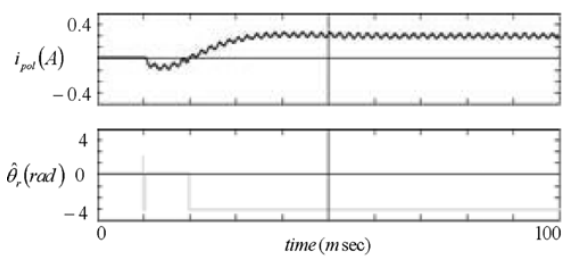

(d)

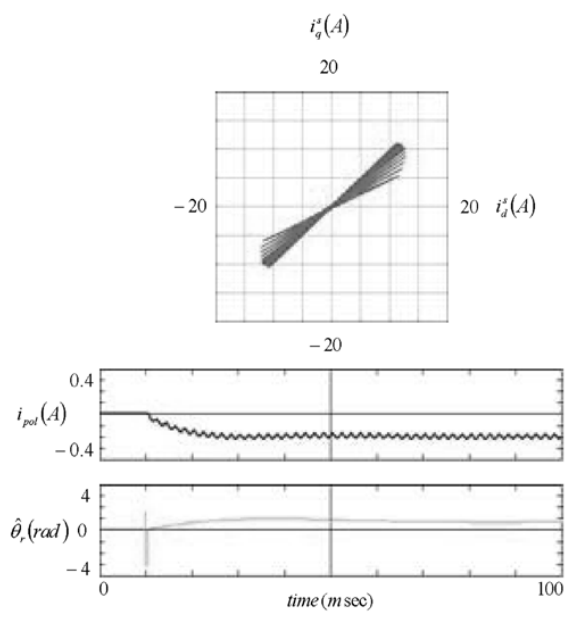

(b)

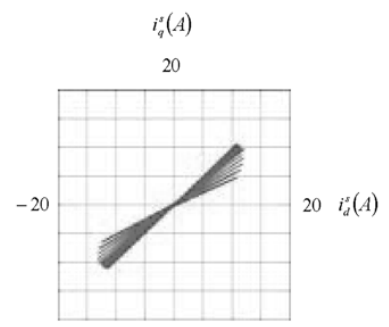

$-20$
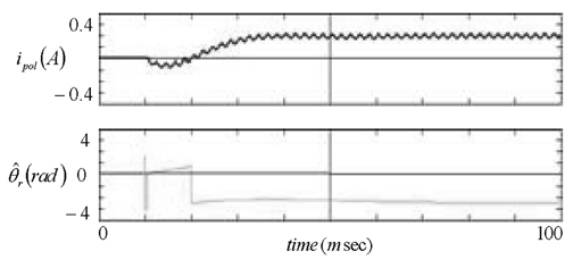

(e)

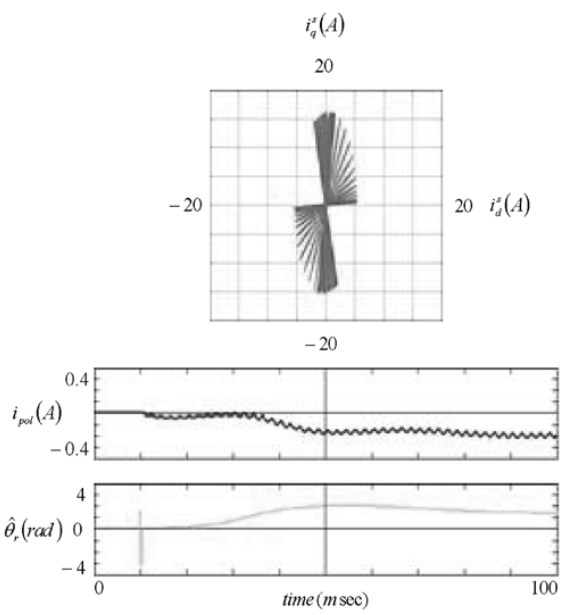

(c)

$i_{q}^{s}(A)$

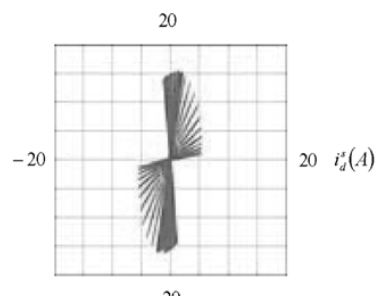

$-20$
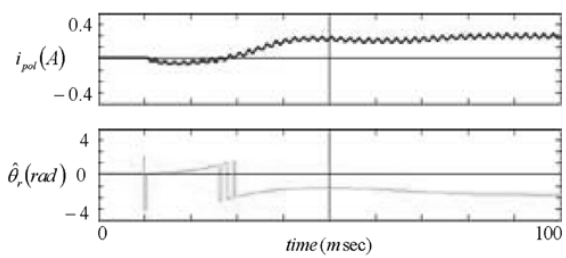

(f)

Fig. 6. Oscillating vector injection at multiples of $0.25 \pi \mathrm{rad}$ (simulation). (a) $0 \mathrm{rad}$. (b) $0.25 \pi \mathrm{rad}$. (c) $0.5 \pi \mathrm{rad}$. (d) $-\pi \mathrm{rad}$. (e) $-0.75 \pi \mathrm{rad}$. (f) $-0.5 \pi \mathrm{rad}$.

estimation, e.g., the electromagnetic torque command is used as the natural feedforward input and this observer also inherently produces an estimate of the load torque as the form of a state filter [11]. The bandwidth of the load torque estimate depends on the observer gains which are typically selected by balancing noise attenuation and estimation bandwidth. This signal enables implementation of disturbance input decoupling to further improve the disturbance rejection performance of the system.

To analyze the observer, a properly formed operating point model is used. If the position error is small enough to yield acceptable linearity, the estimation accuracy can be expressed as follows:

$$
\frac{\hat{\theta}_{r}(s)}{\theta_{r}(s)}=\frac{\frac{\hat{t}_{e}}{t_{e}} \cdot \frac{J}{P} s^{3}+\frac{V_{c}}{\omega_{c}}\left(\frac{1}{L_{d}}-\frac{1}{L_{q}}\right)\left(K_{d} s^{2}+K_{p} s+K_{i}\right)}{\frac{\hat{J}}{P} s^{3}+\frac{V_{c}}{\omega_{c}}\left(\frac{1}{L_{d}}-\frac{1}{L_{q}}\right)\left(K_{d} s^{2}+K_{p} s+K_{i}\right)}
$$

where $J$ stands for the inertia of the IPM synchronous machine and $P$ denotes pole pairs and the circumflex denotes the estimated quantity. From (12), it can be seen that the effect of in- ertia variation is only significant at high frequencies where the torque feedforward input is dominant.

It is important to note that the observer will have more than one stable point, because its actual input is periodic function of the position error. Using the operating point model developed from the observer in Fig. 4, it is possible to develop the expression of the corresponding multiple positions where zero tracking error can occur.

$$
\hat{\theta}_{r}=\theta_{r}+\frac{n \pi}{2} .
$$

The angles given by odd values of $n$ are angles where the error signal is zero but the observer will not be locally stable. The angles given by even values of $n$ are angles where the error signal is zero and the observer is locally stable. In particular, values of $n$ that are multiples of 4 identify the angles where a north pole is located. When the estimated rotor position is a north pole of the rotor magnet, the polarity term of the position observer found in the upper block of Fig. 4 is negative, and the resulting estimated angle does not change. If the estimated angle corresponds to a south pole, the polarity term becomes positive, adding $\pi$ rad in electrical angle to the estimated rotor position. 


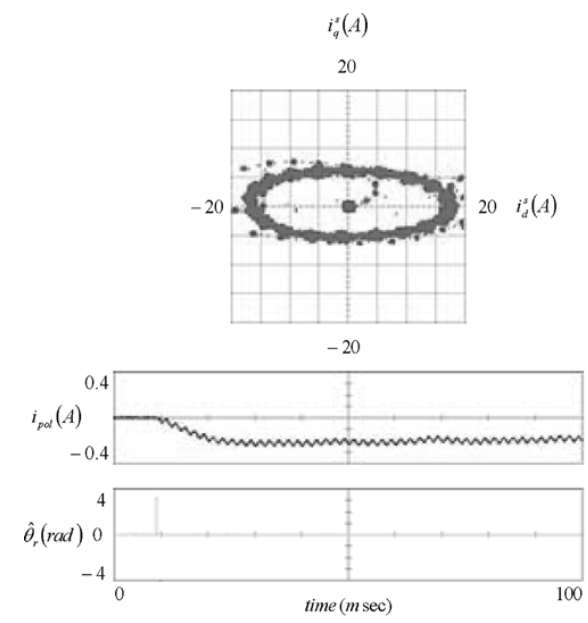

(a)

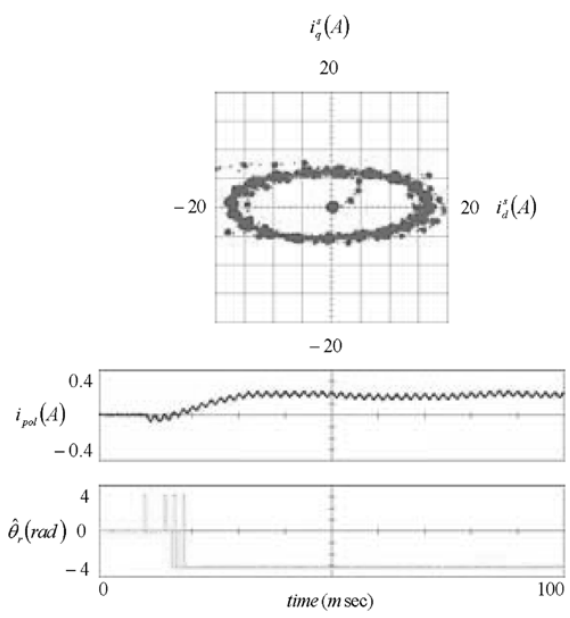

(d)

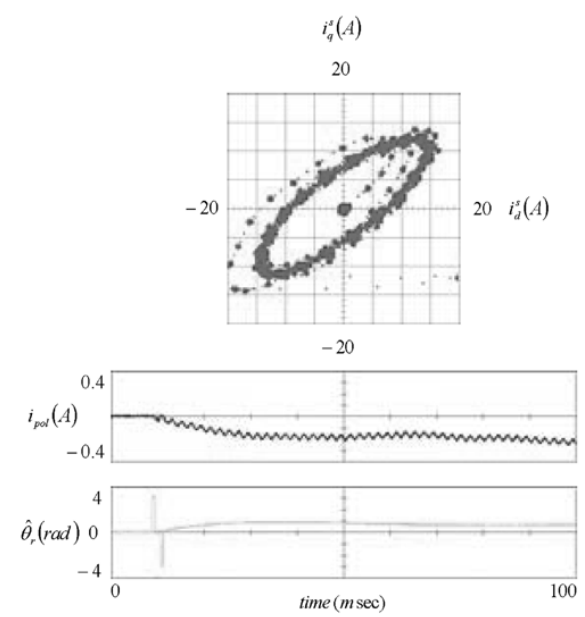

(b)

$i_{q}^{\prime \prime}(A)$
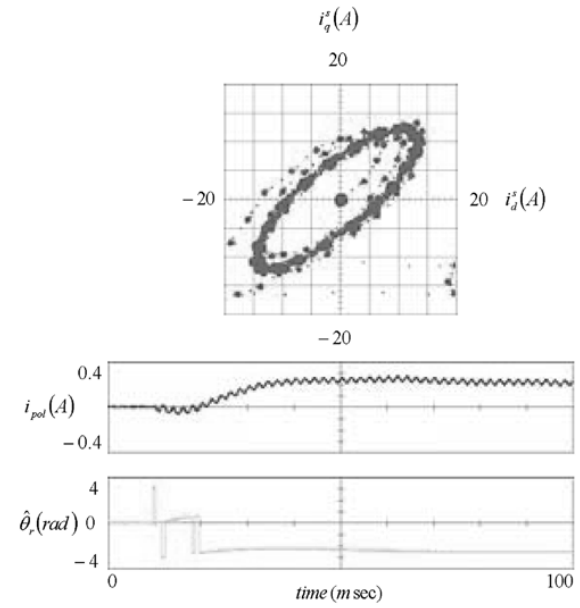

(e)

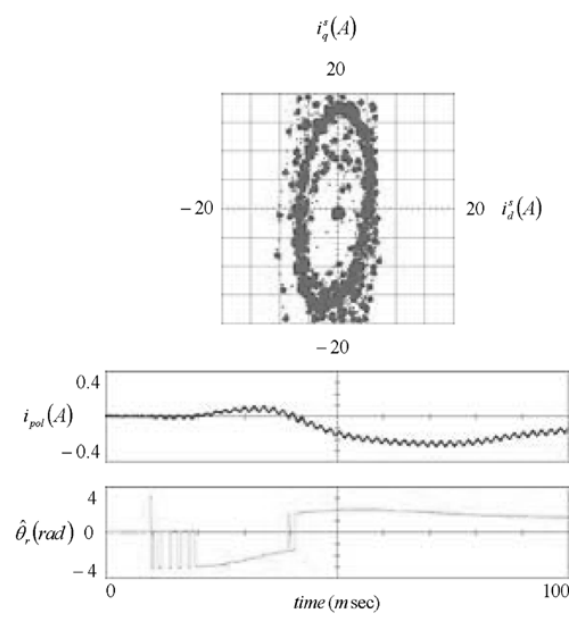

(c)

$i_{q}^{i}(A)$

20
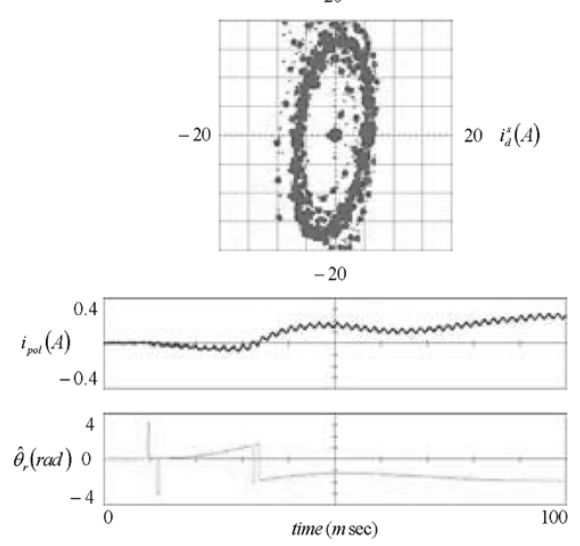

(f)

Fig. 7. Rotating vector injection at multiples of $0.25 \pi \mathrm{rad}$ (experiment). (a) $0 \mathrm{rad}$. (b) $0.25 \pi \mathrm{rad}$. (c) $0.5 \pi \mathrm{rad}$. (d) $-\pi \mathrm{rad}$. (e) $-0.75 \pi \mathrm{rad}$. (f) $-0.5 \pi \mathrm{rad}$.

\section{Simulation AND EXPERIMENT}

The initial rotor position estimation scheme has been investigated using computer simulation and lab experiments. Matlab/Simulink was used for the simulation. The IPM synchronous machine used in this simulation and the experiment is an integrated starter/alternator for automotive applications [12]. The machine parameters are shown in Table I. The carrier voltage for both methods has the amplitude of $5 \mathrm{~V}$ and the frequency of $500 \mathrm{~Hz}$. The amplitude of the second harmonic term is set to $1 \%$ of the carrier frequency component in the simulation.

Position estimation by injecting a rotating vector in the stationary reference frame and that by injecting an oscillating vector in the estimated rotor reference frame at the several positions are depicted Figs. 5 and 6, respectively. The loci of the current vectors in the stationary reference frame are shown in $x-y$ plots which are followed by the current component that contains the polarity information and the last channel shows the estimated rotor position. The loci of the current vector in steady state are either the same ellipse by the rotating voltage vector in the stationary reference frame or the same line by the oscillating voltage vector in the estimated rotor reference frame at both of the initial rotor positions $\pi \mathrm{rad}$ apart from each other but the polarity components have the opposite sign, i.e., negative at a north pole and positive at a south pole.

The characteristics of the position observer were also verified by experiments using a digital-signal-processor (DSP)-based control system. The switching frequency for the FETs is 10 $\mathrm{kHz}$, and the dc-link voltage is $42 \mathrm{~V}$. The carrier voltage is the same as that of the simulation. It should be noted that the delay-time compensation for the accurate heterodyning process is crucial due to the high carrier frequency [13].

Experimental estimation characteristics at the same initial position as the simulation by both of the high-frequency injection methods are depicted in Figs. 7 and 8. The fundamental component currents are separated from the carrier signals and controlled in the estimated rotor reference frame, which was not considered in the simulation. The results in the experiments match well with those of the simulation.

\section{CONCLUSION}

This paper has introduced a technique using a sinusoidal voltage as is typically used as the carrier signal in self-sensing control implementation for estimating the rotor position of an IPM synchronous machine that is appropriate at standstill, including magnetic polarity identification. The approach utilizes 


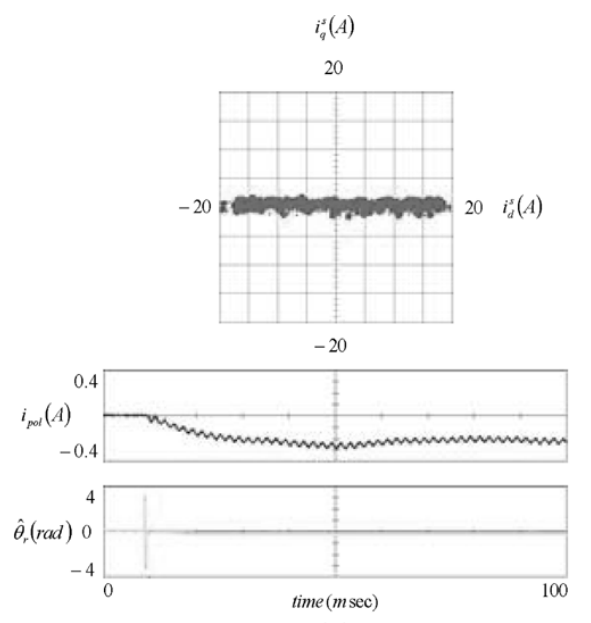

(a)

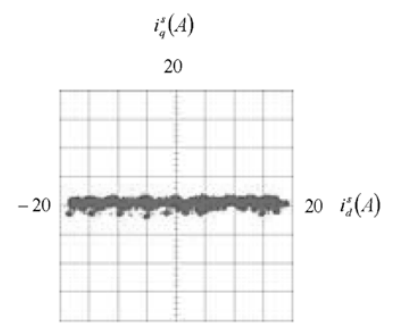

$-20$
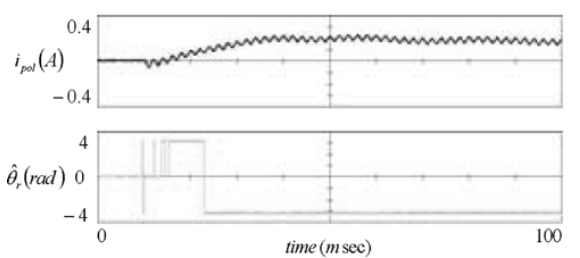

(d)

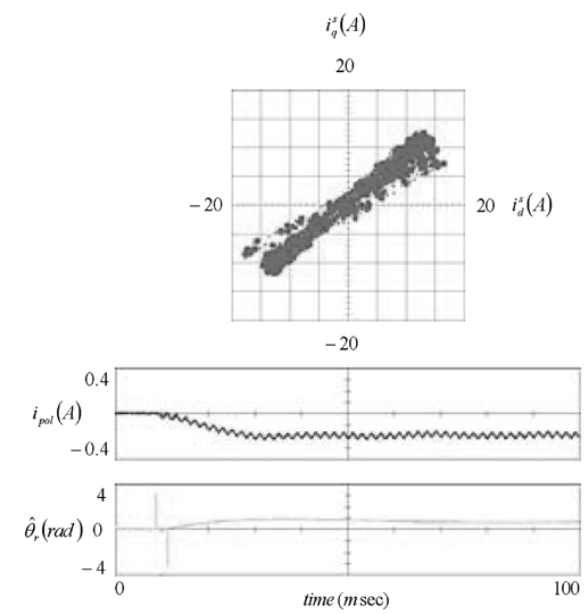

(b)

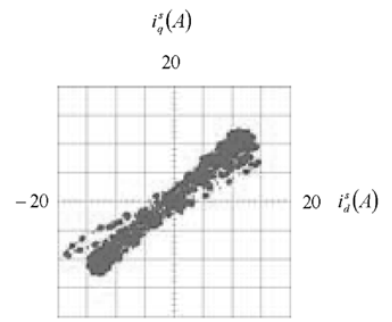

$-20$

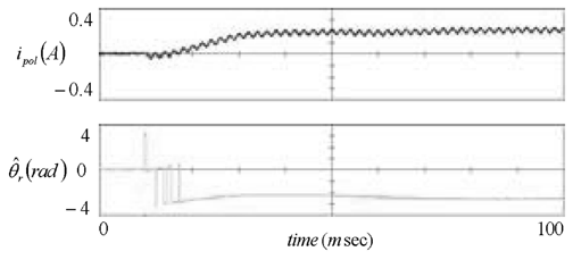

(e)

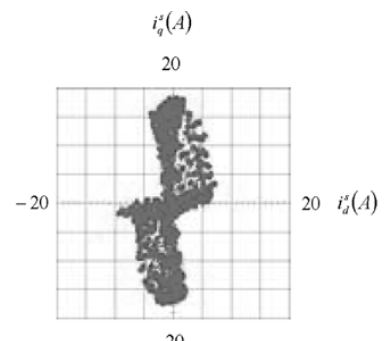

$-20$

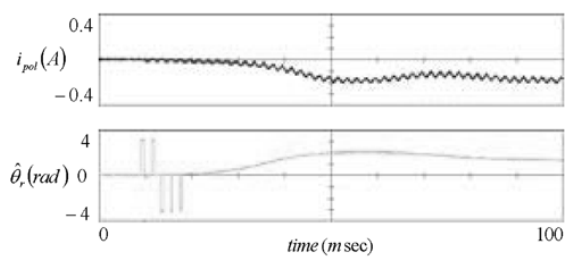

(c)

$i_{q}^{t}(A)$
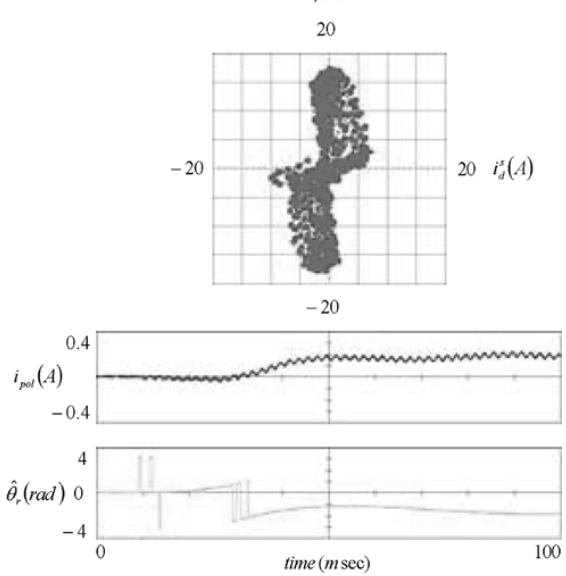

(f)

Fig. 8. Oscillating vector injection at multiples of $0.25 \pi \mathrm{rad}$ (experiment). (a) $0 \mathrm{rad}$. (b) $0.25 \pi \mathrm{rad}$. (c) $0.5 \pi \mathrm{rad}$. (d) $-\pi \mathrm{rad}$. (e) $-0.75 \pi \mathrm{rad}$. (f) $-0.5 \pi \mathrm{rad}$.

magnetic saturation that is modeled using the second harmonic component of the carrier frequency in order to distinguish the polarity of the rotor magnet.

The simulation and the experimental results have demonstrated that this technique is effective using either a rotating vector in the stationary reference frame or an oscillating vector in the estimated rotor reference frame.

The magnitude of the carrier voltage for magnetic polarity detection depends on the saturation level due to the rotor magnet. Therefore, it should be applied with large enough magnitude to detect the magnet polarity at standstill, and once the polarity detected, it can be reduced for the normal sensorless operation.

\section{REFERENCES}

[1] T. M. Jahns, G. B. Kliman, and T. W. Neumann, "Interior permanentmagnet synchronous motors for adjustable-speed drives," IEEE Trans. Ind. Appl., vol. 22, no. 4, pp. 738-747, July/Aug. 1986.

[2] P. L. Jansen and R. D. Lorenz, "Transducerless position and velocity estimation in induction and salient AC machines," IEEE Trans. Ind. Appl., vol. 31, no. 2, pp. 240-247, Mar./Apr. 1995.

[3] M. W. Degner and R. D. Lorenz, "Using multiple saliencies for the estimation of flux, position and velocity in AC machines," IEEE Trans. Ind. Appl., vol. 34, no. 5, pp. 1097-1104, Sep./Oct. 1998.
[4] M. J. Corley and R. D. Lorenz, "Rotor position and velocity estimation for a salient-pole permanent magnet synchronous machine at standstill and high speeds," IEEE Trans. Ind. Appl., vol. 34, no. 4, pp. 784-789, Jul./Aug. 1998.

[5] J. Ha and S. Sul, "Sensorless field-orientation control of an induction machine by high-frequency signal injection," IEEE Trans. Ind. Appl., vol. 35, no. 1, pp. 45-51, Jan./Feb. 1999.

[6] S. Kondo, A. Takahashi, and T. Nishida, "Armature current locus-based estimation method of rotor position of permanent magnet synchronous motor without mechanical sensor," in Conf. Rec. IEEE-IAS Annu. Meeting, 1995, pp. 55-60.

[7] P. B. Schmidt, M. L. Gaspery, G. Ray, and A. H. Wijenayake, "Initial rotor angle detection of a nonsalient pole permanent magnet synchronous machine," in Conf. Rec. IEEE-IAS Annu. Meeting, 1997, pp. 459-463.

[8] J. Kim and S. Sul, "New standstill position detection strategy for PMSM drive without rotational transducers," in Conf. Rec. IEEE APEC'94, 1994, pp. 363-369.

[9] D. Chung, J. Kang, and S. Sul, "Initial rotor position detection of PMSM at standstill without rotational transducer," in Conf. Rec. IEEE IEMDC'99, 1999 , pp. 785-787.

[10] J. Ha, K. Ide, T. Sawa, and S. Sul, "Sensorless rotor position estimation of an interior permanent-magnet motor from initial states," IEEE Trans. Ind. Appl., vol. 39, no. 3, pp. 761-767, May/Jun. 2003.

[11] R. D. Lorenz, "Observers and state filters in drives and power electronics," J. Elect. Eng., vol. 2, pp. 4-12, 2002.

[12] W. L. Soong, N. Ertugrul, E. C. Lovelace, and T. M. Jahns, "Investigation of interior permanent magnet offset-coupled automotive integrated starter/alternator," in Conf. Rec. IEEE-IAS Annu. Meeting, 2001, pp. 429-436.

[13] B. Bae and S. Sul, "A compensation method for time-delay of full-digital synchronous frame current regulator of PWM AC drives," IEEE Trans. Ind. Appl., vol. 39, no. 3, pp. 802-810, May/Jun. 2003. 


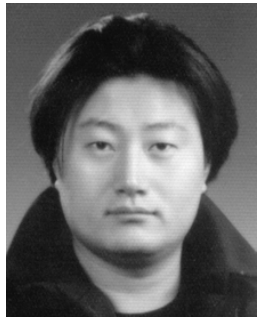

Yu-seok Jeong (S'01) was born in Daegu, Korea, in 1971. He received the B.S. and M.S. degrees in electrical engineering in 1993 and 1995, respectively, from Seoul National University, Seoul, Korea, where he is currently working toward the Ph.D. degree, pursuing fault-tolerant control and robust adaptive control of interior permanent-magnet synchronous machine drives in collaboration with General Motors..

He joined the Kia Motors Technical Center, Seoul, Korea, as a Research Engineer in 1995. At Kia, he worked to develop ac motor drive systems for electric/hybrid vehicles. In 1999, he joined the Korea Electrical Engineering and Science Research Institute, Seoul, Korea, where he worked on single-converter-multi-inverter control design for crane applications. He spent a year as a Special Student at the University of Wisconsin, Madison. His interests include digital control of power electronics and energy conversion.

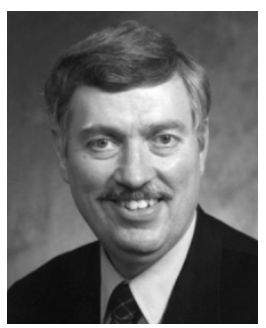

Robert D. Lorenz (S'83-M'84-SM'91-F'98) received the B.S., M.S., and Ph.D. degrees from the University of Wisconsin, Madison, and the M.B.A. degree from the University of Rochester, Rochester, NY.

Since 1984, he has been a member of the faculty of the University of Wisconsin, Madison, where he is the Mead Witter Foundation Consolidated Papers Professor of Controls Engineering in both the Department of Mechanical Engineering and the Department of Electrical and Computer Engineering. He is Co-Director of the Wisconsin Electric Machines and Power Electronics Consortium, which celebrated its 20th anniversary in 2001. It is the largest industrial research consortium on motor drives in the world. He is also the thrust leader for control and sensor integration in the Center for Power Electronic Systems, an NSF Engineering Research Center (ERC) which is a joint ERC with Virgina Polytechnic Institute and State University, Rensselaer Polytechnic Institute, University of Puerto Rico-Mayaguez, and North Carolina A\&T. From 1972 to 1982, he was a member of the research staff at the Gleason Works, Rochester, NY, working principally on high-performance drives and synchronized motion control. He was a Visiting Research Professor in the Electrical Drives Group, Catholic University of Leuven, Leuven, Belgium, in the summer of 1989 and in the Power Electronics and Electrical Drives Institute, Technical University of Aachen, Aachen, Germany, in the summers of 1987, 1991, 1995, 1997, and 1999, where he also was the SEW Eurodrive Guest Professor from September 1, 2000 until July 7, 2001. In 1969-1970, he conducted Master thesis research in adaptive control of machine tools at the Technical University of Aachen. His current research interests include sensorless electromagnetic motor/actuator technologies, real-time signal processing and estimation techniques, precision multiaxis motion control, and ac/dc drive and high-precision machine control technologies. He has authored more than 160 published technical papers and is the holder of 16 patents, with two more pending.

Dr. Lorenz was the IEEE Industry Applications Society (IAS) President for 2001, a Distinguished Lecturer of the IAS for 2000/2001, immediate past Chair of the IAS Awards Department, and past Chairman of the IAS Industrial Drives Committee, and is a member of the IAS Industrial Drives, Electric Machines, Industrial Power Converter, and Industrial Automation and Control Committees. $\mathrm{He}$ is also the current Chair of the Periodicals Committee for the IEEE Technical Activities Board. He is a member of the IEEE Sensor Council AdCom. He was awarded the 2003 IEEE IAS Outstanding Achievement award, which honors his outstanding contributions and technological developments in the application of electricity to industry. He has won 15 prize paper awards. He is a Member of the American Society of Mechanical Enginees, Instrument Society of America, and The International Society for Optical Engineers. He is a Registered Professional Engineer in the States of New York and Wisconsin.

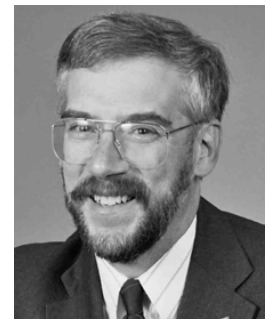

Thomas M. Jahns (S'73-M'79-SM'91-F'93) received the S.B. and S.M. degrees in 1974 and the $\mathrm{Ph} . \mathrm{D}$. degree in 1978 from Massachusetts Institute of Technology, Cambridge, all in electrical engineering.

In 1998, he joined the faculty of the University of Wisconsin, Madison, as a Professor in the Department of Electrical and Computer Engineering, where he is also an Associate Director of the Wisconsin Electric Machines and Power Electronics Consortium (WEMPEC). Prior to joining the University of Wisconsin, he was with GE Corporate Research and Development, Schenectady, NY, for 15 years, where he pursued new power electronics and motor drive technology in a variety of research and management positions. His research interests include permanent-magnet synchronous machines for a variety of applications ranging from high-performance machine tools to low-cost appliance drives. During 1996-1998, he conducted a research sabbatical at Massachusetts Institute of Technology, where he directed research activities in the area of advanced automotive electrical systems and accessories as co-director of an industry-sponsored automotive consortium.

Dr. Jahns was awarded the William E. Newell Award by the IEEE Power Electronics Society (PELS) in 1999. He has been recognized as a Distinguished Lecturer by the IEEE Industry Applications Society (IAS) during 1994-1995 and by PELS during 1998-2000. He has served as President of PELS (1995-1996) and as a Member of the IAS Executive Board between 1992-2001. He was elected Director/Delegate of IEEE Division II, serving during 2002-2003 on the IEEE Board of Directors.

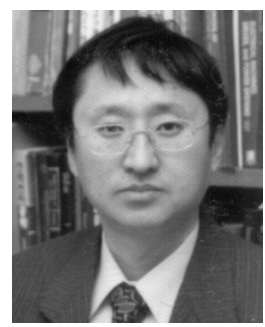

Seung-Ki Sul (S'78-M'80-SM'98-F'00) was born in Korea in 1958. He received the B.S., M.S., and $\mathrm{Ph} . \mathrm{D}$. degrees in electrical engineering from Seoul National University, Seoul, Korea, in 1980, 1983, and 1986, respectively.

From 1986 to 1988, he was an Associate Researcher with the Department of Electrical and Computer Engineering, University of Wisconsin, Madison. From 1988 to 1990, he was a Principal Research Engineer with Gold-Star Industrial Systems Company. Since 1991, he has been a member of the faculty of the School of Electrical Engineering, Seoul National University, where he is currently a Professor. His current research interests are power-electronic control of electric machines, electric/hybrid vehicle drives, and power-converter circuits. 